\title{
$\mathrm{F}$ 급 전력증폭기의 출력 전력 불확도에 대한 $\mathrm{DC}$ 영향 분석 및 최적 바이어스 조건 도출에 관한 연구
}

\section{Analysis on the Propagated Uncertainty of Output Power of Class-F Power Amplifiers from DC Biasing and Its Optimization}

\author{
박 영 철·윤 회 진* \\ Youngcheol Park $\cdot$ Hoijin Yoon* \\ 요 약
}

본 논문은 $\mathrm{F}$ 급 무선 전력증폭기의 설계에 있어 바이어스 전압의 불확도가 출력 전력에 미치는 영향을 분석하고, 이를 최소화하는 바이어스 조건을 도출하였다. 이를 위하여 불확도 전파이론을 활용하여 전력증폭기의 출력 전력에 대한 드 레인 및 게이트 바이어스 공급 전압의 불확도가 전파되는 영향에 대하여 이론적인 해석 및 측정 민감도에 대해 분석하였 으며, $1.9 \mathrm{GHz}$ 에서 동작하는 $\mathrm{F}$ 급 전력증폭기 회로에서의 전력 불확도에 대한 이론적, 실험적 분석 방법을 제시하였다. 더불어, 증폭기의 성능을 유지하면서 출력 불확도를 최소화하기 위한 최적의 바이어스 조건을 도출하였다. 그 결과, 1.17 $\mathrm{W}$ 출력 전력에 대한 전원 공급 장치의 전압 불확도는 바이어스 조건에 따라 약 $15 \sim 65 \mathrm{~mW}$ 의 영향을 미치는 것으로 파악되었으며, 최적 바이어스 조건으로 측정할 경우 출력 전력은 $0.37 \mathrm{~dB}$ 감소하는 반면에 출력 불확도는 $15 \mathrm{~mW}$ 이하로 감소시킬 수 있음을 확인하였다.

\section{Abstract}

In this paper, the propagation effect of power supply uncertainty on the output of class-F power amplifier has been estimated. Also, a $1.9 \mathrm{GHz}, 10$ watt class-F power amplifier was measured to verify the estimation and to find the optimal biasing point. By approximating the propagation theory of uncertainties, the propagation effect of bias uncertainty was mathmatically calculated. As a result, the DC biases have propagated uncertainties of $15 \sim 70 \mathrm{~mW}$. However, at the optimized bias point, the uncertainty in the output power could be dropped less than $15 \mathrm{~mW}$ while the output power has dropped by $0.37 \mathrm{~dB}$.

Key words: Uncertainty, Power Amplifier, Propagation of Uncertainty

I. 서 론

향후 예상되는 무선 통신 기기의 급격한 보급에 대비 하여 정밀한 무선 통신장치를 효율적으로 생산/테스트하
기 위한 연구가 활발하게 진행되고 있다. 이 때의 테스트 시간과 정확성은 제품 생산성에 직접적인 영향을 미치게 되며 ${ }^{[1]}$, 그 중 전력증폭기는 상대적으로 높은 출력을 담 당하는 부품이기에, 설계 및 제조상의 오차로 인한 불확

「이 연구는 2013학년도 한국외국어대학교 교내 연구비의 지원에 의하여 이루어졌음.

한국외국어대학교 전자공학과(Department of Electronics Engineering, Hankuk University of Foreign Studies)

*협성대학교 컴퓨터공학과(Department of Computer Science and Engineering, Hyupsung University)

- Manuscript received November 15, 2013 ; Revised January 22, 2014 ; Accepted January 22, 2014. (ID No. 20131115-113)

· Corresponding Author: Youngcheol Park (e-mail: ycpark@hufs.ac.kr) 
도가 시스템의 고속 대량 생산 시 부정확한 합격/불합격 판정에 미치는 영향이 매우 크다고 할 수 있다. 그러나 일 반적인 무선 시스템의 출력 불확도 분석의 경우 매우 제 한된 조건에서의 결과만이 제시되어 일반적인 증폭기 시 스템의 출력에 대한 영향을 정확하게 예측하기가 사실 상 불가능한 상황이다[2],[3]. 따라서, 본 고에서는 회로 시 뮬레이션을 활용한 $\mathrm{A}$ 급 전력증폭기의 출력 불확도 분석 을 확장하여 ${ }^{[4]}$, 고효율 $\mathrm{F}$ 급 무선 전력증폭기의 출력 성능 에 영향을 미치는 외부 인자에 대하여 연구하였다. 그 중 에서도 대표적인 외부 인자인 게이트 및 드레인 바이어 스가 주요한 인자로 예상되는 바 ${ }^{[4]}$, 통합 시스템에서의 바이어스 전압 불확도가 출력 전력의 불확도로 전파되는 경로에 대해 이론적인 해석을 활용하였으며 실험을 통하 여 이를 확인하였다. 마지막으로 위의 분석 및 측정을 활 용하여 출력 전력, 효율, 전력 불확도 등을 고려 한 최적 의 바이어스 조건을 도출하였다.

\section{F-급 전력증폭기}

일반적인 전력증폭기의 출력 전압 및 전류는 다음의 고조파 성분의 조합으로 표현될 수 있다 ${ }^{[5]}$.

$$
\begin{aligned}
v_{D} & =V_{D D}+\operatorname{Re}\left(\sum_{k} j \cdot v_{k} e^{-j k \omega_{o} t}\right) \\
& =V_{D D}+\operatorname{Re}\left(\sum_{k} \overline{V_{k}}\right) \\
i_{D} & =I_{d c}+\operatorname{Re}\left(\sum_{k} j \cdot i_{k} e^{-j k \omega_{o} t}\right) \\
& =I_{d c}+\operatorname{Re}\left(\sum_{k} \overline{I_{k}}\right),
\end{aligned}
$$

여기서, $v_{k}$ 와 $i_{k}$ 는 각각 드레인 전압과 전류의 평준화 된 고조파 신호 성분이다.

또한, 드레인 출력 전력은 다음과 같은 비선형 transconductance $g_{m}$ 과 비선형 계수 $\alpha_{k}$ 로 근사화하여 표현할 수 있다.

$$
i_{D}=g_{m} v_{i n} \simeq \sum_{k=0}^{N} i_{k}=\sum_{k=0}^{N} \alpha_{k} v_{i n}^{k}
$$

특히, $\mathrm{F}$ 급 전력증폭기의 경우 1 차 고조파를 제외한 홀 수 고조파 임피던스는 무한대, 짝수 고조파 임피던스는 0
을 만족하여 이론적인 효율 $100 \%$ 를 이루게 된다.

결과적으로, 1 차 고조파 출력 전력 $P_{o, 1}$ 은 다음과 같이 드레인에서의 1 차 고조파 출력 전압 $v_{1}$ 과 전류 $i_{1}, 1$ 차 고 조파 부하저항 $R_{L}$ 및 트랜지스터 비선형 파라미터의 복 합작용으로서 아래 식과 같이 표현된다.

$$
P_{o, 1}=\frac{1}{2} R_{L}\left|i_{1}\right|^{2}=\frac{1}{2} \frac{\left|v_{1}\right|^{2}}{R_{L}} .
$$

\section{F-급 전력증폭기에서의 출력 전력 불확도}

측정 불확도(Uncertainty)란, 특정 시스템의 운용 및 측 정에 있어서 주어진 조건 하에 예상되는 오차의 범위 및 이의 제시 절차를 의미한다 ${ }^{[6]}$. 전력증폭기의 출력 불확도 의 경우, 증폭기의 출력 포트에서 측정되거나 수신되는 전력이 중심 값을 기준으로 불규칙적으로 변화하는 정도 를 확률적인 신뢰수준으로 표현한다. 따라서, 전력증폭기 출력 전력에서의 불확도의 경우, 시스템을 구성하는 부품 의 설계, 제조상의 오차와 같은 회로적인 변동 조건과 더 불어, 공급 전력의 불확도 또한 최종 전력의 동작을 결정 하는 중요 요소가 될 수 있다. 그 중에서도 RF 트랜지스 터의 특성 상 높은 수준의 trans-conductance가 요구되기 에, 게이트 바이어스에서의 전압 불안정성 혹은 불확도는 증폭기 시스템에 가장 큰 영향을 미칠 것으로 예상된다. 이와 더불어, 증폭기의 출력을 결정하는 드레인 전압은 시스템에서 가장 높은 전압을 공급하기에 이의 불확도 또한 중요한 분석대상으로서 제시한 바 있다 ${ }^{[4]}$.

게이트 및 드레인에서의 바이어스 공급 전압을 증폭기 출력의 주요 외부 영향인자로 설정할 경우, 최종적인 출 력 불확도는 다음과 같이 RSS(Root-Sum-Square) 방식을 따르는 불확도 전파 법칙으로 표현할 수 있다 ${ }^{[6]}$.

$$
\left(U_{P_{o}}\right)^{2} \approx\left(\frac{\partial P_{o}}{\partial V_{G G}}\right)^{2}\left(U_{V_{G G}}\right)^{2}+\left(\frac{\partial P_{o}}{\partial V_{D D}}\right)^{2}\left(U_{V_{D D}}\right)^{2},
$$

여기서, $U_{P_{o}}$ 는 출력 전력의 불확도, $U_{V_{G G}}$ 는 게이트 바이 어스의 전압 불확도, $U_{V_{D D}}$ 는 드레인 바이어스의 전압 불 확도이다.

더불어, 앞의 식 (5)에서 언급된 1차 고조파 출력 전력 
에 대하여 $\mathrm{F}$ 급 전력증폭기가 설계되는 경우, 일반적으로 다음과 같은 1 차 고조파 전압 및 전류조건이 성립한다. 이 때 식 (4)의 비선형 계수 $\alpha_{k}$ 는 게이트 바이어스 $V_{G G}$ 의 종속함수가 되어 불확도 결정인자로서 확장된다.

$$
\begin{aligned}
& v_{1}=\frac{4}{\pi} \frac{V_{D D}-v_{\text {knee }}}{2} \beta, \\
& i_{1}=\alpha_{1}\left(V_{G G}\right) v_{i n}
\end{aligned}
$$

여기서 $v_{k n e e}$ 는 드레인에서의 knee 전압, $\beta$ 는 출력 포화 계수(saturation factor, $0 \leq \beta \leq 1$ )이다.

위의 식 (4) 및 식 (6)로부터 게이트 및 드레인 전압의 불확도가 출력 전력 불확도로 전파되는 성분을 개별적으 로 도출할 경우, 출력 전력의 게이트 전압 민감도는 다음 과 같이 유도할 수 있다.

$$
\frac{\partial P_{o}}{\partial V_{G G}}=\frac{\partial P_{o}}{\partial i_{1}} \frac{\partial i_{1}}{\partial V_{G G}}=\left(R_{L} i_{1}\right) \frac{\partial i_{1}}{\partial V_{G G}} .
$$

이 때, 위 식의 $\frac{\partial i_{1}}{\partial V_{G G}}$ 항에 있어, 입력 전압 $v_{i n}$ 과 게 이트 바이어스 $V_{G G}$ 가 서로 독립 변수라고 가정할 경우, 다음과 같이 근사화 할 수 있다.

$$
\begin{aligned}
\frac{\partial i_{1}}{\partial V_{G G}} & =\frac{\partial}{\partial V_{G G}}\left[\alpha_{1}\left(V_{G G}\right) v_{i n}\right] \\
& =\frac{\partial \alpha_{1}\left(V_{G G}\right)}{\partial V_{G G}} v_{i n}+\alpha_{1}\left(V_{G G}\right) \frac{\partial v_{i n}}{\partial V_{G G}}, \\
& \approx \frac{\partial \alpha_{1}\left(V_{G G}\right)}{\partial V_{G G}} v_{i n}=\alpha_{1}^{\prime} v_{i n}
\end{aligned}
$$

여기서 $\alpha_{1}{ }^{\prime}$ 은 $\alpha_{1}$ 의 $V_{G G}$ 성분에 대한 1 차 도함수 값 이다.

위의 식에서 1차 trans-conductance $\alpha_{1}$ 은 트랜지스터의 $I \sim V$ 관계식과 $\mathrm{F}$ 급 증폭기에서 반파 사인파 전류의 $\mathrm{Fo}-$ urier 계수 비율을 활용하여 다음과 같이 근사화 하여 표 현할 수 있다.

$$
\begin{aligned}
\alpha_{1}=\frac{\partial i_{1}}{\partial v_{\mathrm{in}}} & \approx \frac{\partial i_{D S}}{\partial v_{g s}}\left(\frac{i_{1}}{i_{D S}}\right) \\
& \approx \frac{\partial}{\partial v_{g s}}\left[\eta\left(V_{G G}+v_{g s}-V_{T H}\right)^{2}\right] \\
& \approx 2 \eta\left(V_{G G}+v_{g s}-V_{T H}\right),
\end{aligned}
$$

여기서 $\eta$ 는 비례상수로, 위 식에서 드레인 출력 전류 $i_{1}$, 게이트 입력 $\mathrm{AC}$ 전압 $v_{g s}$ 및 $\mathrm{DC}$ 전압 $V_{G G}$ 를 활용하여 추정할 수 있다.

또한, 위 식 (9)를 활용하면 $\alpha_{1}{ }^{\prime}=\frac{\partial \alpha_{1}}{\partial V_{G G}}=2 \eta$ 로 표 현되며, 결과적으로 게이트 바이어스의 불확도에 의한 출 력 전력 불확도(식 (5)의 첫 번째 항)은 다음과 같이 표현 된다.

$$
\left(\frac{\partial P_{o}}{\partial V_{G G}}\right)^{2}\left(U_{V_{G G}}\right)^{2} \approx\left(R_{L} i_{1} \alpha_{1}{ }^{\prime} v_{i n}\right)^{2}\left(U_{V_{G G}}\right)^{2} .
$$

위 식으로부터, 1차 trans-conductance $\alpha_{1}$ 은 게이트 바 이어스에 대한 강한 변곡 함수임을 감안할 때 큰 $\alpha_{1}{ }^{\prime}$ 를 가지게 되고, 결과적으로 출력 전력 불확도에 많은 영향 을 미침을 알 수 있다. 결과적으로, 식 (10)은 게이트 바이 어스의 변화에 대한 출력 전력 변화량을 나타낸다.

위와 유사한 방법으로 드레인 바이어스의 불확도에 대 한 출력 전력의 민감도는 역시 식 (4) 및 식 (6)을 활용하 여 다음과 같이 유도할 수 있다.

$$
\begin{aligned}
\frac{\partial P_{o}}{\partial V_{D D}} & =\frac{\partial}{\partial V_{D D}} \frac{\left|v_{1}\right|^{2}}{2 R_{L}} \\
& =\frac{\partial}{\partial V_{D D}}\left[\frac{1}{2 R_{L}}\left(\frac{4 \beta}{\pi} \frac{V_{D D}-v_{\text {knee }}}{2}\right)^{2}\right] \\
& =\frac{4 \beta^{2}}{\pi^{2} R_{L}}\left(V_{D D}-v_{\text {knee }}\right)
\end{aligned}
$$

따라서, 드레인 바이어스의 불확도에 의한 출력 전력 불확도 영향인자(식 (6)의 두 번째 항)은 다음과 같다.

$\left(\frac{\partial P_{o}}{\partial V_{D D}}\right)^{2}\left(U_{V_{D D}}\right)^{2}=\left(\frac{4 \beta^{2}}{\pi^{2} R_{L}}\left(V_{D D}-v_{k n e e}\right)\right)^{2}\left(U_{V_{D D}}\right)^{2}$.

결과적으로 위의 식은 드레인 바이어스의 변화에 대한 출력 전력 변화량을 표현하며, 출력 저항 값이 작을수록, 출력 전력이 최대치에 가까울수록 해당 불확도가 높아지 는 것을 예상할 수 있다.

위에서 얻은 식 (10)과 식 (12)를 RSS 방식으로 합성하 여 최종적인 1- $\sigma$ 분포 수준의 출력 불확도를 산출할 수 있으며, 이를 2배함으로써 2- $\sigma$ 분포 수준 $(95 \%$ 신뢰수 
준)의 출력 불확도를 제시하게 된다.

\section{IV. 출력 전력 불확도 시뮬레이션}

본 절에서는 앞에서의 수학적 접근 방법을 활용하여 $\mathrm{F}$ 급 전력증폭기를 대상으로 출력 전력 불확도를 분석하 였다.

본 분석에 활용된 전력증폭기는 그림 1 의 $\mathrm{F}$ 급 회로로 설계되었으며, 상용 $10 \mathrm{~W}$ 급 $\mathrm{GaN}$ 소자를 기반으로 최대 효율 $82 \%$ 를 내도록 설계되었다. 동 증폭기의 정상적인 드레인 바이어스는 $28 \mathrm{~V}$ 이며, 게이트 바이어스는 약 $-2.7 \mathrm{~V}, 1.9 \mathrm{GHz}$ 에서의 출력 저항은 약 21 옴이다. 이상 의 바이어스 조건에서 해당 트랜지스터는 약 $218 \mathrm{~mA}$ 의 드레인 전류를 흘리며, 선형 영역에서 최대 약 $15.2 \mathrm{~dB}$ 의 전력 gain 가지는 것으로 파악되었다. 증폭기는 일반적인 통신신호 증폭 조건을 고려하여 최대전력 대비 약 $10 \mathrm{~dB}$ back-off를 감안하여 분석하였다 $(\beta=0.34)$. 위와 같이 주어 진 동작 조건 및 식 (9)를 활용하여 $\alpha_{1}=0.274(\mathrm{mho})$, $\alpha_{1}{ }^{\prime}=0.457(\mathrm{mho} / \mathrm{V})$ 를 산출하였다.

또한, 실제 측정에 사용되는 바이어스 전원장치의 규 격을 바탕으로 전원 공급장치가 각각 $\pm(0.05 \%+20 \mathrm{mV})$ (게이트 전원), $\pm(0.5 \%+10 \mathrm{mV})$ (드레인 전원)의 불확도 를 가지는 경우를 산정하여 증폭기의 출력 전력에 대한 개별 전원의 불확도 영향과 최종적으로 RSS 방식으로 합 성된 불확도를 예상하였으며, 이는 표 1에서와 같이 나타 낼 수 있다. 표 1 에서 나타난 바와 같이, 바이어스 전원에 의한 출력 전력의 불확도는 $39.3 \mathrm{~mW}$ 로, 그 중 게이트 바 이어스의 영향은 $38.2 \mathrm{~mW}$, 드레인 바이어스의 영향은 9.3

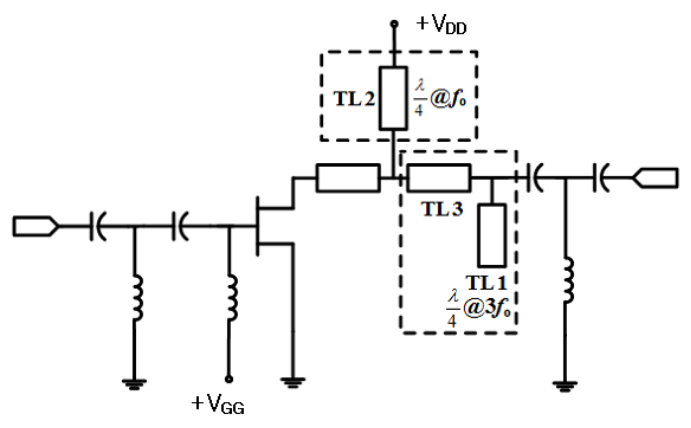

그림 1. 분석에 활용된 $\mathrm{F}$ 급 전력증폭기 회로도

Fig. 1. Class-F amplifier used for the analysis.
표 1. DC 바이어스 변동에 의한 수학적 불확도 시뮬레 이션 분석 결과

Table 1. Estimated uncertainty in output power from biasing voltages.

\begin{tabular}{|c|c|}
\hline 불확도 인자 & $\begin{array}{c}\text { 출력 전력으로 전파된 } \\
\text { 불확도( } 95 \% \text { 신뢰수준 })\end{array}$ \\
\hline $\begin{array}{c}\text { 게이트 바이어스 }\left(V_{G G}\right): \\
-2.7 \mathrm{~V} \pm(0.05 \%+20 \mathrm{mV})\end{array}$ & 0.0093 watt \\
\hline $\begin{array}{c}\text { 드레인 바이어스 }\left(V_{D D}\right): \\
28 \mathrm{~V} \pm(0.5 \%+10 \mathrm{mV})\end{array}$ & $0.0382 \mathrm{watt}$ \\
\hline $\mathrm{RSS}$ 합성 불확도 & 0.0393 watt \\
\hline
\end{tabular}

$\mathrm{mW}$ 으로 분석되었다.

\section{$\mathrm{V}$. 출력 전력 불확도 측정 및 분석}

앞 절의 시뮬레이션 분석에 활용된 $1.9 \mathrm{GHz} F$ 급 전력 증폭기에 대하여 출력 전력의 불확도에 대하여 측정 및 분석하였다. 분석은 크게 두 가지로 나눠진다. 우선, 바이 어스 전압의 변화에 따른 평균 출력 전력의 변화량을 분 석하여 개별 바이어스 변화에 대한 민감도를 분석하고, 다음으로는 출력 전력에서의 합성 불확도를 추정한다. 이 를 통하여 증폭기의 출력 전력이 바이어스에 의해 어느 정도의 변동성을 나타내는지를 추정할 수 있다.

바이어스 전압의 민감도를 산출하기 위하여 게이트 바

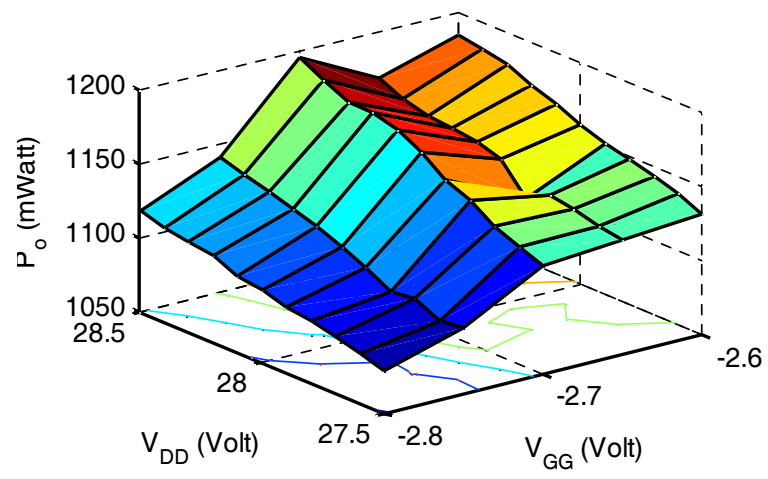

그림 2. 바이어스 전압 변동에 따른 $\mathrm{F}$ 급 전력증폭기의 평 균 출력 전력 변화 $\left(V_{D D}: 27.5 \sim 28.5 \mathrm{~V}, V_{G G}\right.$ : -2.85 $\sim-2.65 \mathrm{~V}$ )

Fig. 2. Variation of average output power of a class-F amplifier over the variation of $\mathrm{DC}$ bias voltages $\left(V_{D D}\right.$ : $\left.27.5 \sim 28.5 \mathrm{~V}, V_{G G}:-2.85 \sim-2.65 \mathrm{~V}\right)$. 


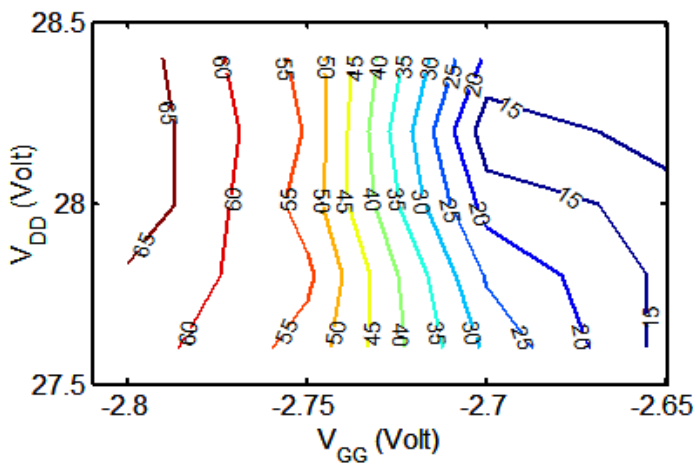

그림 3. 바이어스에 따른 $\mathrm{F}$ 급 전력증폭기의 출력 불확도 변화(단위: $\mathrm{mW}$ ).

Fig. 3. Propagated uncertainty from bias to the output power(unit: $\mathrm{mW}$ ).

이어스 $V_{G G}$ 는 $-2.8 \sim-2.6 \mathrm{~V}$ 의 범위에서 $0.5 \mathrm{~V}$ 간격으로 측정하였으며, 드레인 바이어스 $V_{D D}$ 는 $27.5 \sim 28.5 \mathrm{~V}$ 범위 에서 $0.1 \mathrm{~V}$ 간격으로 측정하였다. 측정 간의 상관 관계를 최소화하기 위하여 개별 측정은 전체 바이어스 범위에 대해 10 분 간격으로 총 5 회 수행하여 분석하였다. 그 결 과, 그림 3은 드레인 전압의 변화에 따른 평균 출력 전력 변화를 나타낸다. 본 그림으로부터 평균 출력 전력은 주 어진 게이트 및 드레인 바이어스의 변화에 대하여 공히 약 $80 \mathrm{~mW}$ 의 변화량을 나타내는 것을 알 수 있다.

이에 비하여 출력 전력의 불확도를 분석한 결과, 바이 어스 조건에 따라 약 15 65 $\mathrm{mW}$ 의 불확도를 나타내는 것을 확인할 수 있다(그림 3). 또한 그림 3으로부터 출력 전력의 불확도는 주로 게이트 바이어스 $V_{G G}$ 에 민감한 영 향을 받음을 알 수 있다. 즉, $V_{G G}$ 가 $-2.7 \mathrm{~V}$ 보다 낮을수록 출력 불확도는 $65 \mathrm{~mW}$ 까지 급격하게 증가하는 반면, -2.7 $\mathrm{V}$ 보다 높은 경우 출력 불확도는 약 $20 \mathrm{~mW}$ 정도로 안정 적인 값을 가짐을 확인할 수 있다. 이는 앞 절에서의 시뮬 레이션 결과와 동일한 추세이다. 다만, $V_{D D}=28 \mathrm{~V}$ 및 $V_{G G}=$ $-2.7 \mathrm{~V}$ 에서 계산된 합성 출력 불확도가 $39.3 \mathrm{~mW}$ 인 반 면, 측정 결과는 약 $17.7 \mathrm{~mW}$ 로 차이를 보이고 있다. 이는 $\alpha_{1}{ }^{\prime}$ 계수 산출시의 근사화 오차가 원인으로 추정되며, $V_{G G}=-2.73 \mathrm{~V}$ 인 경우의 측정 결과와 매우 유사한 결과, 나타내고 있는 것으로 보아 $V_{G G}$ 관련 계수 산출에서 약 $1 \%(0.03 \mathrm{~V})$ 의 오차가 발생한 것으로 판단된다. 그림 4 는

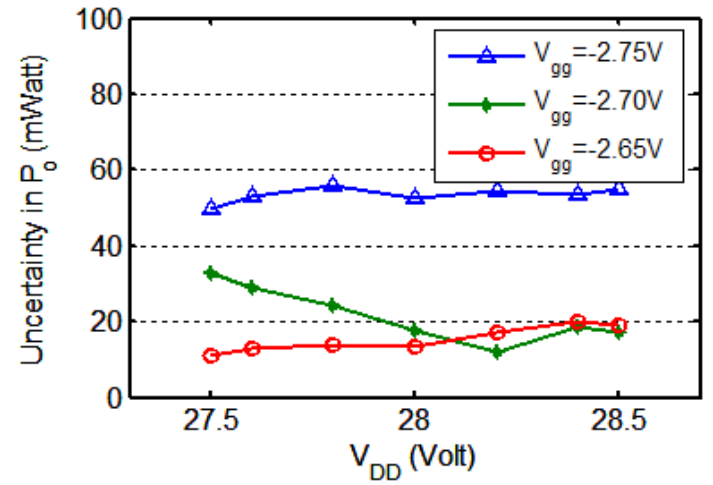

(a) $V_{G G}=-2.7 \mathrm{~V}$ 고정 시

(a) $V_{G G}=-2.7 \mathrm{~V}$

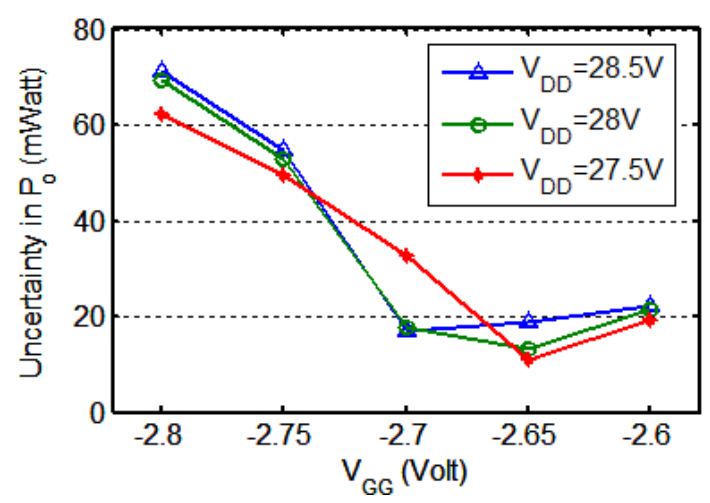

(b) $V_{D D}=28 \mathrm{~V}$ 고정 시

(b) $V_{D D}=28 \mathrm{~V}$

그림 4. $V_{G G}$ 변동에 따른 $\mathrm{F}$ 급 전력증폭기의 출력 불확도 변화(2- $\sigma)$

Fig. 4. Propagated uncertainty of gate bias to the output power of a class-F amplifier.

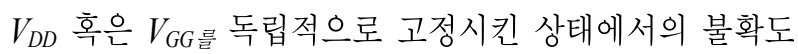
변화 추이를 나타낸다. 그림 4 에서 측정된 최소 불확도인 약 $15 \mathrm{~mW}$ 는 전체 측정 시스템에 있어 전원을 제외한 불 확도 영향인자(계측기 불확도, 케이블 부정합 등)에 의한 불확도 결과로 유추할 수 있다.

위와 같은 측정 결과를 기반으로 출력 전력을 유지하 면서 불확도를 최소화 할 수 있는 바이어스를 선정할 수 있다. 특히 $V_{D D}=28 \mathrm{~V}, V_{G G}=-2.65 \mathrm{~V}$ 를 트랜지스터에 바이 어스 전압으로 인가할 경우, 출력은 약 $0.01 \mathrm{watt}$ 정도(약 $0.37 \mathrm{~dB})$ 감소하나, 출력 불확도는 0.015 watt 이하로 개선 시킴을 확인할 수 있다(그림 2 및 그림 3 참조). 


\section{VI. 결 론}

본 논문은 $\mathrm{F}$ 급 무선 전력증폭기의 설계에 있어, 증폭기 의 출력 전력에 대한 드레인 및 게이트 바이어스 전압의 불확도 영향에 대하여 수학적 해석 및 측정을 통하여 분 석하였다. 분석에 활용된 전력증폭기는 $1.9 \mathrm{GHz}$ 에서 동 작하는 $\mathrm{F}$ 급 증폭기로, 바이어스 전압의 변동에 따른 전력 불확도에 대한 이론적, 실험적 분석을 제시하였다. 그 결 과, 증폭기의 trans-conductance은 게이트 전원의 불확도 전파에 영향을 미치며, 출력 포화계수는 드레인 전원의 불확도 전파에 영향을 미침을 확인할 수 있었다. 또한, $1.17 \mathrm{~W}$ 출력 전력에 대한 전원 공급 장치의 전압 불확도 는 바이어스 조건에 따라 약 15 65 mW의 영향을 미치 는 것으로 파악되었으며, 최적 바이어스 조건의 경우 출 력 전력은 $0.37 \mathrm{~dB}$ 감소하는 반면에, 출력 불확도는 15 $\mathrm{mW}$ 이하로 감소시킬 수 있음을 확인하였다.

\section{References}

[1] K. B. Schaub, J. Kelly, Production Testing for RF and
박 영 철

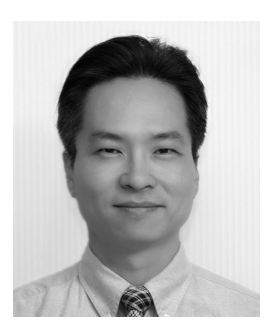

1992년 2월: 연세대학교 전기공학과 (공학 사)

2004년 7월: Georgia Inst. Tech. 전기컴퓨 터공학과 (공학박사)

2004년 2007년: 삼성전자 정보통신 총괄 책임연구원

2007년 3월 현재: 한국외국어대학교 전

자공학과 교수

[주 관심분야] 전력증폭기 설계, 디지털 무선 신호처리, 무선 측정시스템 불확도 해석

System-on-a-Chip Devices for Wireless Communications, Artech House, pp. 33-93, 2004.

[2] Rodhe \& Schwartz(2012, Mar.). RF Level Measurement Uncertainties with the Measuring Receiver R\&S FSMR. [Online], Available: http://www2.rohde-schwarz.com/file/ 1MA92_0e.pdf

[3] Swanzy, Joe, "Impact of VSWR on the uncertainty analysis of harmonics for a scope calibrator instrument", in Proc. of Workshop and Symp. of National Conf. and Standards Laboratories, pp. 663-670, 2002.

[4] Y. Park, "Analysis and control of uncertainty in wireless transmitting devices", in SecTech/CA/CES-CUBE 2012, Jeju, vol. 339, pp. 438-445, 2012.

[5] Y. Park, "Class-F technique as applied to active frequency multiplier designs", IEEE Trans. Microwave Theory and Tech., vol. 57, no. 12, pp. 3212-3218, Dec. 2009.

[6] JCGM : "Evaluation of measurement data: Guide to the expression of uncertainty in measurement", Technical Document, 100:2008, 2008.

윤 회 진

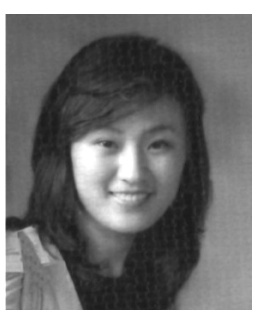

1992년 2월: 이화여자대학교 컴퓨터공학 과 (공학사)

2004년 2월: 이화여자대학교 컴퓨공학과 (공학박사)

2007년 9월 현재: 협성대학교 컴퓨터공 학과 교수

[주 관심분야] 무선신호 처리 시스템 소프 트웨어 개발 및 테스팅 